\title{
Evaluation of earth fault location algorithm in medium voltage distribution network with correction technique
}

\author{
N. S. B. Jamili, M. R. Adzman, S. R. A. Rahim, S. M. Zali, M. Isa, H. Hanafi \\ School of Electrical System, Universiti Malaysia Perlis, Malaysia
}

\begin{tabular}{l}
\hline \hline Article Info \\
\hline Article history: \\
Received Jun 9, 2016 \\
Revised Nov 20, 2016 \\
Accepted Dec 11, 2016 \\
\hline Keywords: \\
ATP software \\
Correction technique \\
Fault location \\
Medium voltage distribution \\
network
\end{tabular}

\begin{abstract}
This paper focused on studying an algorithm of earth fault location in the medium voltage distribution network. In power system network, most of the earth fault occurs is a single line to ground fault. A medium voltage distribution network with resistance earthing at the main substation and an earth fault attached along the distribution network is modeled in ATP Draw. The generated earth fault is simulated, and the voltage and current signal produced is recorded. The earth fault location algorithm is simulated and tested in MATLAB. The accuracy of the earth fault location algorithm is tested at several locations and fault resistances. A possible correction technique is explained to minimize the error. The results show an improvement fault location distance estimation with minimum error.
\end{abstract}

Copyright () 2019 Institute of Advanced Engineering and Science. All rights reserved.

\section{Corresponding Author:}

N. S. B. Jamili,

School of Electrical System Engineering,

Universiti Malaysia Perlis,

Pauh Putra Campus, 02600 Arau, Perlis, Malaysia.

Email: nurshazlin@studentmail.unimap.edu.my

\section{INTRODUCTION}

The medium voltage distribution network is the most sensitive part of the distribution network. It is because most of the blackout experienced by customers is caused by disturbances in the medium voltage network. Mostly, weather changes cases are the main reason for the electrical power supply disturbance, especially for the overhead lines that located in the forests. Thus a reliable network is required due to the increased use of electricity [1].

The fault may happen at any point in a power system. The fault that occurs on power system was classified as a symmetrical fault and unsymmetrical faults. The symmetrical fault is where all three phases of the transmission line are shorted together. While unsymmetrical faults can be divided into three categories; single line-to-ground, line-to-line and double line-to-ground fault. Earth fault accounts for about $80 \%$ of the distribution network faults, which makes the detecting and locating of single-phase earth fault important [2].

Based on [3], the researcher studied the instantaneous single-phase-to-earth fault that occurs, and the fault arc that disappears automatically because of the rapid compensation of arc suppression coil current. To solve that problem, they used TSC (Thyristor Switched Capacitors) automatic tuning arc suppression coil with a parallel resistor. While in [4] studies explained about the unreliability of the localization criterions in Polish medium voltage power distribution networks. A new adaptive algorithm based on the wavelet analysis enabling detection of specific dynamics of the measuring signal during intermittent earth faults is produced. In [5] studies about an earth fault distance estimation by using transient signal but more focused on isolated and compensated neutral in medium voltage network. Work in [6] proposed a scheme to locate an earth fault in unearthed or a compensated neutral medium voltage (MV) network using transient signal recorded from MV/LV substations. The algorithm applies continuous wavelet Transform (CWT) to locate the dominant 
charge transient frequency and then fast Fourier transform (FFT) to extract coefficients to be used in the fault location scheme.

Another researcher [7], studies about high-impedance faults (HIFs) which produce a small fault current, thus not detectable by some overcurrent protection devices. To solve that problem, the researcher analyzed the data by converting the harmonic analysis of current waveforms in the MATLAB by using Fourier transform. Also, researcher in [8] studies about detection and identification of high impedance faults in power networks, but the researcher used the wavelet output to construct a detection criterion and used an algorithm to determine the faulted phase and feeder.

According to [7], fault location techniques for distribution networks have been classified into three different groups: fundamental frequency measurements, high-frequency measurements and the use of artificial intelligence (AI). Referring to [9], the short-circuit fault, reliable earth fault indicators are lacking, and the fault distance computation is still an open issue for utilities. Based on researcher work in [9] the researcher uses voltage and a current signal; prefault, fault, and post-fault to find the fault location. Figure 1 shows the network model used for fault distance calculation.

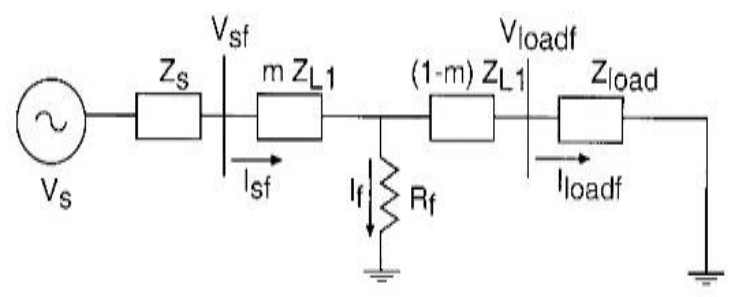

Figure 1. Simple schema of the network model used for fault distance calculation [10]

Based on [11] studies, the researcher modeled the network in PSDAC/EMTDC which has studied on the simulation, varying ground resistivity, fault resistance, fault type and the location of the fault. The researcher uses prefault and fault signal to find the location of the fault. Figure 2 shows the simulated voltage and currents signal in prefault and fault conditions during a single line-to-ground fault with a fault resistance of $5 \Omega$.

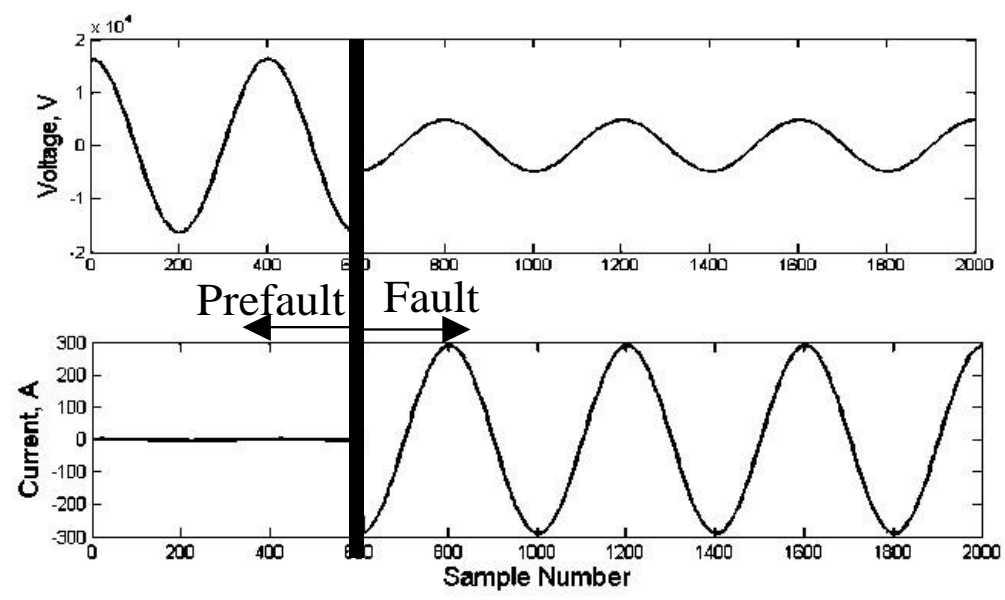

Figure 2. Simulated voltage and current signal during single line to ground fault

\section{RESEARCH METHOD}

Figure 3 shows the schematic diagram of modelled simple power network modeled in ATP draw. It consists of three phase source alternating current (AC), step down transformer, three-phase distribution line, and load. 


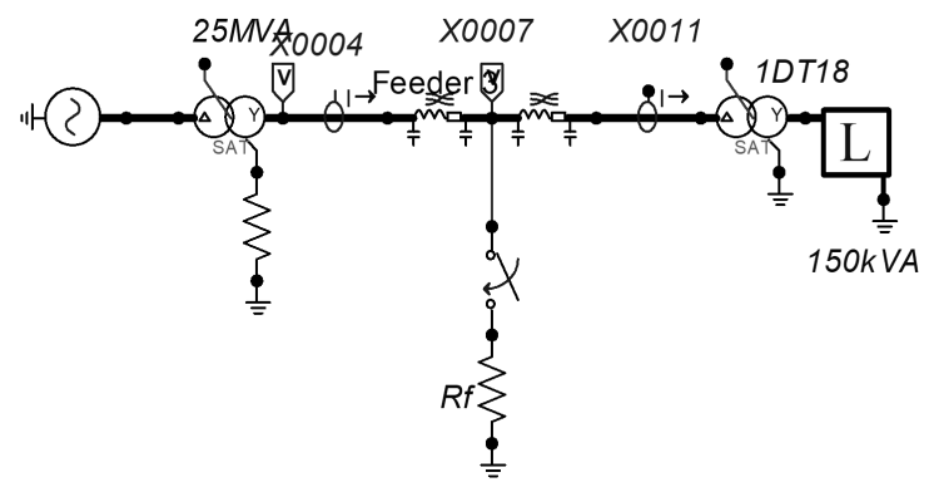

Figure 3. Schematic diagram of simple power network modeled in ATPDraw

\subsection{Fault location algorithm} developed.

According to [12], based on the equivalent circuit shown in Figure 4, fault location estimation (1) is

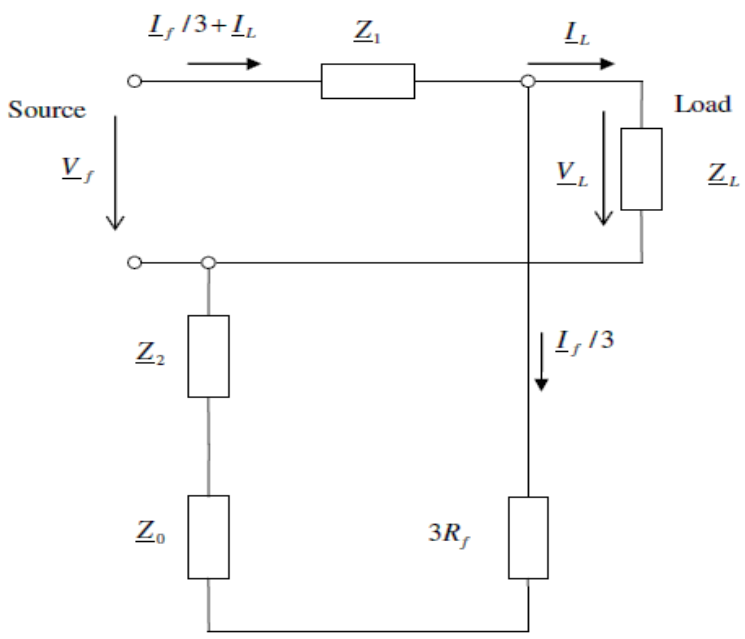

Figure 4. The symmetrical component model of a radially operated network for the conventional fault location method

$$
\text { Fault_Location }=\frac{\frac{V_{f}}{I_{f}}-R_{f}}{\frac{1}{3}\left(Z_{0}+Z_{1}+Z_{2}\right)+\frac{I_{L}}{I_{f}} Z_{1}}
$$

$V_{f}$ is the fault phase voltage, $I_{f}$ is the fault current, $I_{L}$ is the load current, $Z_{0}, Z_{1}$, and $Z_{2}$ are the zero-, positive- and negative- sequence impedances of the line per $\mathrm{km}$, and $R_{f}$ is the fault resistance. In [13], a fault resistance value can be determined by using (2). $R_{f}$ is the fault resistance, $V_{s}$ is the fault phase voltage and $I_{s}$ is the fault current.

$$
R_{f}=\frac{V_{s}}{I_{s}}
$$

\subsection{Correction factor}

To minimize the error of fault location and fault resistance, a linear and parabolic regression is used to generate equations. From curve fitting application tool in MATLAB, under 'APPS' section, a statistical 
solution can be developed. By using method of least squares, the coefficients $m$ (slope) and $b$ (y-intercept) of the straight line equation can be formed.

$$
y=m x+b
$$

Figure 5 shows the line fit plot based on Table 1 data. The straight line is plot by using the actual value versus the calculated value. The straight line equation formed is used as correction factor in this work. It is used to minimize the earth fault location error. Table 1 shows an example data used to develop equation to minimize the fault resistance error. While Table 2 shows the summary of the fitted line plot in Figure 5.

Table 1. Sample Data of Fault Resistance

\begin{tabular}{cc}
\hline Actual Value $(\Omega)$ & Calculated Value $(\Omega)$ \\
\hline 20 & 22.552 \\
40 & 44.399 \\
60 & 63.082 \\
80 & 83.049 \\
\hline
\end{tabular}

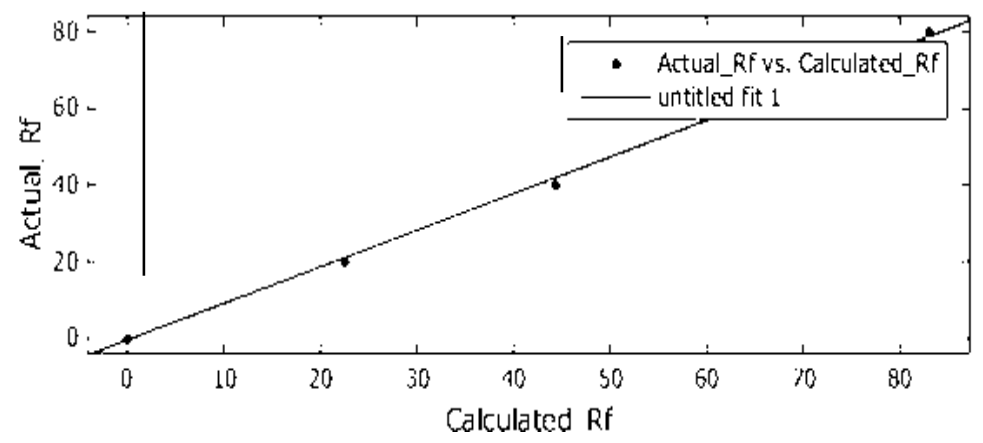

Figure 5. Line fit plot

Table 2. Summary for the Plotted Line Fit

\begin{tabular}{cc}
\hline Linear model Poly1: & $=\mathrm{p} 1{ }^{*} \mathrm{x}+\mathrm{p} 2$ \\
\hline $\mathrm{p} 1$ & $=0.9542(0.9237,0.9846)$ \\
$\mathrm{p} 2$ & $=-0.4144(-1.658,0.8292)$ \\
Goodness of fit: & $=7.13$ \\
SSE & $=0.999$ \\
R-square & $=0.9988$ \\
Adjusted R-square & $=1.09$ \\
RMSE &
\end{tabular}

By referring to Table 2, from [14] error sum of squares (SSE) can be calculated by performing (4). Where $S S T$ is the total sum of squares, SSTR is the treatments sum of squares, while $S S B L$ is the block sum of the squares.

$$
S S E=S S T-S S T R-S S B L
$$

$R$-squared is a statistical measure of how close the data are to the fitted regression line. The definition of $R$-squared is fairly straight-forward; it is the percentage of the response variable variation that is explained by a linear model. Or [15]:

$$
R \text {-squared }=S S T R / S S T
$$

$R$-squared is always between 0 and $100 \%$. $0 \%$ indicates that the model explains none of the variability of the response data around its mean. While $100 \%$ indicates that the model explains all the variability of the response data around its mean. 
As the number of regressors increases, the $R^{2}$ value also increases, so $R^{2}$ cannot be a useful measure for the goodness of model fit. Therefore, $R^{2}$ is adjusted for the number of explanatory variables in the model. The adjusted $R^{2}$ is defined as in equation [16]:

$$
R_{\text {adj }}^{2}=1-\left(1-R^{2}\right) \frac{n-1}{n-p-1}=\frac{(n-1) R^{2}-p}{n-p+1}
$$

The RMSE a way of estimating the difference between the values predicted by a statistical model and the measured values from the actual system [14].

$$
R M S E=\frac{S S E}{(k-1)(n-1)}
$$

The statistical solution for fault resistance less than $100 \Omega$ is given as:

$$
N e w \_R_{f}=\left(R_{f}^{*} 0.9542\right)-0.4144
$$

\subsection{Accurate region}

A cycle of a faulted $V s, I s$ and $I_{L}$ signal consists of 400 samples is used in (1) and the result of fault location estimation is presented in a signal form as shown in Figure 6. Figure 6 shows the estimated fault location at $2 \mathrm{~km}$ from the substation. Fault location is determined by observing the accurate region.

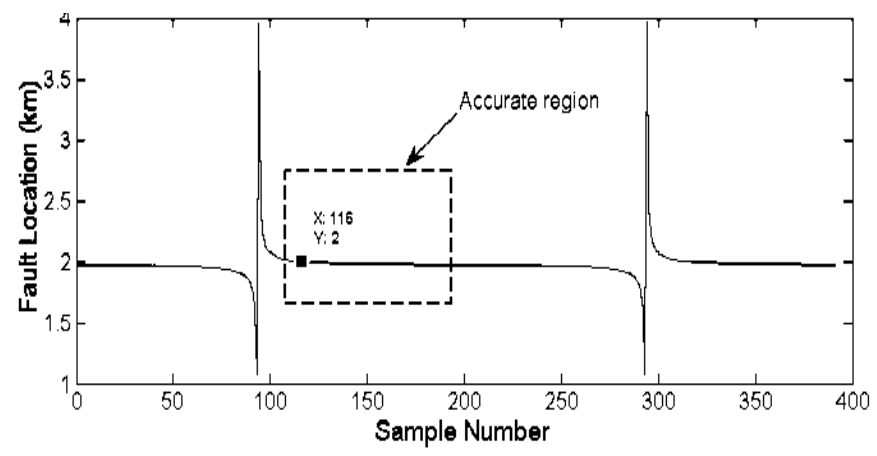

Figure 6. Fault distance estimation for fault at $2 \mathrm{~km}$ from the measuring point

\section{RESULTS AND ANALYSIS}

Several tests have been conducted to test the accuracy and suitability of the algorithm to the circuit.

\subsection{Sampling frequency}

This test was done to find the most suitable method and sampling frequency to locate the fault location. The algorithm has been tested with a sampling frequency of $10 \mathrm{kHz}$ up to $50 \mathrm{kHz}$ with $5 \mathrm{kHz}$ increment. For example, based on accurate region as shown in Figure 6 the median, mean and fix fault distance of that region is $1.982 \mathrm{~km}, 1.984 \mathrm{~km}$ and $2.000 \mathrm{~km}$ respectively. For fix fault distance, the position for data collected is different depends on the number of the samples for tested sampling frequencies, then after a sampling frequency was chosen, the fixed sample number is used for every test. For example, based on Figure 6, 116 is the used sample number. The sampling frequency were tested on four different distances $(2 \mathrm{~km}, 4 \mathrm{~km}, 6 \mathrm{~km}$, and $8 \mathrm{~km})$. The fault resistance used in this simulation is $1 \Omega$, and load of $83 \mathrm{kVA}$. Table 3 shows the result of the simulation and Figure 7 shows the difference in percentage between actual distance and estimated distance with three different methods. 
Table 3. Results of Fault location Estimation tested with Different Sampling Frequencies and Distances

\begin{tabular}{ccccccccccccc}
\hline $\begin{array}{c}\text { Fault } \\
\text { location } \\
\begin{array}{c}\text { Sampling } \\
\text { freq }\end{array}\end{array}$ & Mean & Median & Fix & Mean & Median & Fix & Mean & Median & Fix & Mean & Median & Fix \\
\hline $10 \mathrm{k}$ & 1.975 & 1.974 & 1.999 & 3.959 & 3.957 & 3.999 & 5.942 & 5.940 & 5.999 & 7.925 & 7.921 & 7.999 \\
$15 \mathrm{k}$ & 1.999 & 1.982 & 2.000 & 3.998 & 3.971 & 4.001 & 5.997 & 5.959 & 6.002 & 7.996 & 7.946 & 8.003 \\
$20 \mathrm{k}$ & 1.984 & 1.982 & 2.000 & 3.974 & 3.970 & 4.001 & 5.964 & 5.957 & 6.002 & 7.953 & 7.944 & 8.003 \\
$25 \mathrm{k}$ & 1.989 & 1.985 & 2.000 & 3.982 & 3.976 & 4.002 & 5.975 & 5.966 & 6.003 & 7.968 & 7.956 & 8.004 \\
$30 \mathrm{k}$ & 1.988 & 1.986 & 2.000 & 3.981 & 3.977 & 4.001 & 5.974 & 5.968 & 6.001 & 7.966 & 7.958 & 8.002 \\
$40 \mathrm{k}$ & 1.993 & 1.990 & 2.000 & 3.988 & 3.984 & 4.002 & 5.984 & 5.978 & 6.003 & 7.979 & 7.971 & 8.004 \\
$50 \mathrm{k}$ & 1.993 & 1.991 & 2.000 & 3.989 & 3.985 & 4.001 & 5.985 & 5.980 & 6.002 & 7.980 & 7.974 & 8.003 \\
\hline
\end{tabular}

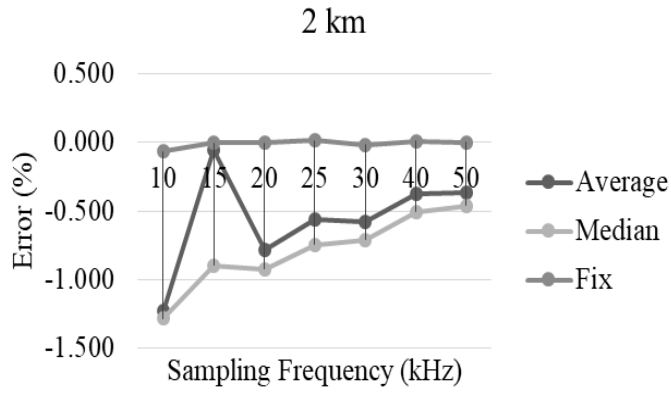

(a)

$6 \mathrm{~km}$

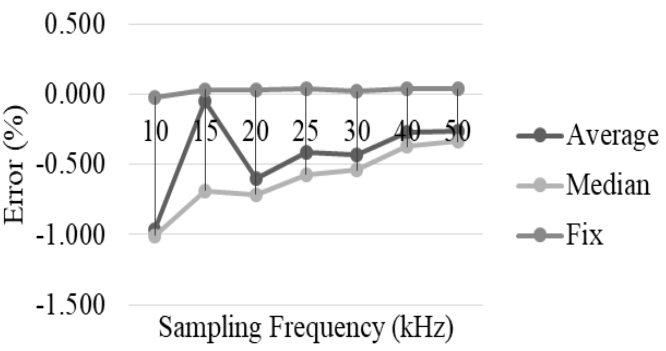

(c)

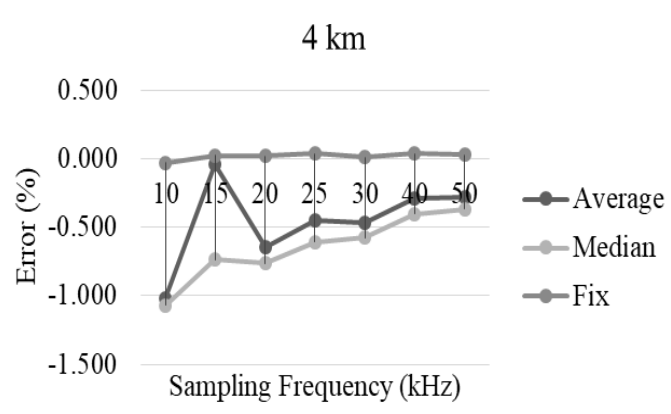

(b)

$8 \mathrm{~km}$

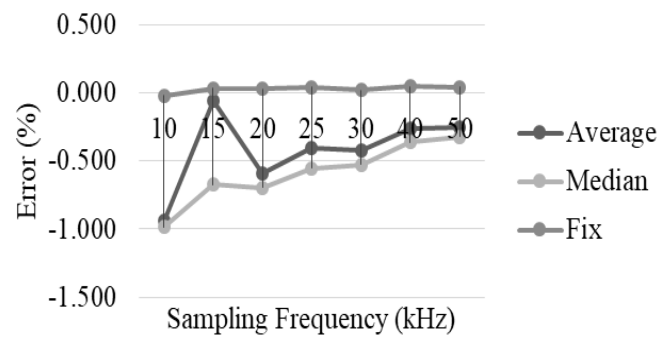

(d)

Figure 7. Graph of percentage of error versus sampling frequency (a) fault at $2 \mathrm{~km}$ (b) fault at $4 \mathrm{~km}$ (c) fault at $6 \mathrm{~km}$, and (d) fault at $8 \mathrm{~km}$

Based on the result obtained as shown in Figure 7, the sampling frequency of $20 \mathrm{kHz}$ and method of fix number were chosen. The selection is based on the most stable, and has the lowest distance error compared to other methods when estimating the earth fault location.

\subsection{Performance evaluation with varies load}

The fault location algorithm was tested with two different loads, 50kVA and 150kVA. The sampling frequency used is $20 \mathrm{kHz}$ and $50 \mathrm{kHz}$. The distance was tested to $2 \mathrm{~km}, 4 \mathrm{~km}, 6 \mathrm{~km}$, and $8 \mathrm{~km}$. Table 4 shows the result obtained from the test. Based on the result shown in Table 4, the algorithm have shown a low error of fault distance. 
Table 4. Result of Fault distance Estimation with difference load condition

\begin{tabular}{ccccc}
\hline Fs & Load & $\begin{array}{c}\text { Fault Distance } \\
(\mathrm{km})\end{array}$ & $\begin{array}{c}\text { Estimated } \\
(\mathrm{km})\end{array}$ & $\begin{array}{c}\text { Errror } \\
(\mathrm{km})\end{array}$ \\
\hline $20 \mathrm{kHz}$ & $50 \mathrm{kVA}$ & 2 & 2.005 & 0.005 \\
& & 4 & 4.010 & 0.010 \\
& & 6 & 6.015 & 0.015 \\
& & 8 & 8.020 & 0.020 \\
& & 2 & 2.009 & 0.009 \\
& & 4 & 4.016 & 0.016 \\
$50 \mathrm{kHz}$ & $50 \mathrm{kVA}$ & 6 & 6.023 & 0.023 \\
& & 8 & 8.030 & 0.030 \\
& & 2 & 2.004 & 0.004 \\
& & 4 & 4.008 & 0.008 \\
& & 6 & 6.012 & 0.012 \\
& & 8 & 8.016 & 0.016 \\
& & 2 & 2.006 & 0.006 \\
& & 4 & 4.011 & 0.011 \\
& & 6 & 6.016 & 0.016 \\
& & 8 & 8.021 & 0.021 \\
\hline
\end{tabular}

\subsection{Fault resistance}

Another factor that affect the accuracy of the algorithm is the fault resistance, $R_{f}$. In this simulation, the actual value of fault resistance is used to find the fault location. Table 5 shows the result of fault location when test with a different value of fault resistance. Based on results in Table 5, the accuracy of the algorithm is accepted.

Table 5. Fault Location Algorithm tested with different value of $R_{f}$ at $90^{\circ}$ Inception angle and load of 50kVA

\begin{tabular}{cccc}
\hline $\begin{array}{c}\text { Distance } \\
(\mathrm{km})\end{array}$ & $\begin{array}{c}\mathrm{Rf} \\
(\mathrm{Ohm})\end{array}$ & $\begin{array}{c}\text { Estimated } \\
(\mathrm{km})\end{array}$ & $\begin{array}{c}\text { Error } \\
(\mathrm{km})\end{array}$ \\
\hline 4 & 0 & 4.010 & 0.010 \\
& 25 & 4.017 & 0.017 \\
& 50 & 4.020 & 0.020 \\
& 100 & 4.018 & 0.018 \\
10 & 0 & 10.028 & 0.028 \\
& 25 & 10.030 & 0.030 \\
& 50 & 10.033 & 0.033 \\
& 100 & 10.029 & 0.029 \\
16 & 0 & 16.030 & 0.030 \\
& 25 & 16.043 & 0.043 \\
& 50 & 16.046 & 0.046 \\
& 100 & 16.042 & 0.041 \\
\hline
\end{tabular}

\subsection{Estimated Fault Resistance}

As mention in [13], the fault resistance can be estimated by using equation (2). Table 6 shows the estimated fault resistance. In Table 6, it shows that estimated fault resistance has small differences compared to the actual value, however it give a huge impact on estimated fault location. It seems that if fault resistance value larger than $100 \Omega$ the error will be huge. This will give huge impact on the fault estimation algorithm. By referring to 2.2, a statistical solution is developed to get the most accurate estimation value.

Table 6. Result of fault resistence estimated

\begin{tabular}{ccc}
\hline Actual $\Omega$ & Estimated $\Omega$ & Error $(\Omega)$ \\
\hline 20 & 22.552 & 2.552 \\
40 & 44.399 & 4.399 \\
60 & 63.082 & 3.082 \\
80 & 83.049 & 3.049 \\
200 & 185.866 & -14.135 \\
400 & 358.038 & -41.962 \\
600 & 551.612 & -48.388 \\
800 & 811.636 & 11.636 \\
\hline
\end{tabular}

Based on the data collected in Table 6, from the estimated value of fault resistance, if the value of the estimated fault resistance is less than $100 \Omega$, (8) will be used to estimate the fault location. However, if the 
value of the estimated fault resistance is equal or larger then $100 \Omega$, (9) will be used. Table 7 shows the result of the estimated fault resistance with correction factor. New_Rf in (8) and (9) were indicated the new estimated $\Omega$ in Table 7 .

New_Rf $=(R f * 0.9567)+43.85$

Based on results in Table 7 , the difference of fault resistance decreases. The smallest error is $0.222 \Omega$ and the largest is $-28.423 \Omega$.

Table 7. Result of Fault Resistance Estimated with Correction Factor

\begin{tabular}{ccc}
\hline Actual $(\Omega)$ & Estimated $(\Omega)$ & Error $(\Omega)$ \\
\hline 20 & 21.105 & 1.105 \\
40 & 41.951 & 1.951 \\
60 & 59.778 & -0.222 \\
80 & 78.831 & -1.169 \\
200 & 221.668 & 21.668 \\
400 & 386.385 & -13.615 \\
600 & 571.577 & -28.423 \\
800 & 820.342 & 20.342 \\
\hline
\end{tabular}

\subsection{Without fault resistance}

The algorithm is also tested if the fault resistance in (1) is negligible. During this test, the load was fixed to $50 \mathrm{kVA}$, and the fault resistance is set to $0 \Omega$. Table 8 shows the estimated fault distance with negligible of fault resistance. The estimated earth fault distance shows a close to the actual fault distance.

Table 8. Results of Estimated earth Fault Distance Without Fault Resistance

\begin{tabular}{ccc}
\hline Actual $(\mathrm{km})$ & Estimated $(\mathrm{km})$ & Error $(\mathrm{km})$ \\
\hline 2 & 2.005 & 0.005 \\
3.7 & 3.709 & 0.009 \\
4 & 4.010 & 0.010 \\
5 & 5.013 & 0.013 \\
6 & 6.015 & 0.015 \\
7.2 & 7.218 & 0.018 \\
8 & 8.020 & 0.020 \\
9.6 & 9.624 & 0.024 \\
10 & 10.025 & 0.024 \\
12 & 12.029 & 0.029 \\
12.5 & 12.531 & 0.031 \\
14 & 14.035 & 0.034 \\
15 & 15.036 & 0.036 \\
16 & 16.038 & 0.038 \\
17.2 & 17.241 & 0.041 \\
18 & 18.044 & 0.044 \\
19.4 & 19.447 & 0.047 \\
20 & 20.049 & 0.049 \\
\hline
\end{tabular}

\section{CONCLUSION}

Fault localization can be determined by analyzing voltage and current faulted signal. Sampling frequency $\left(f_{s}\right)$, fault resistance, unexpectedly can give the minor error effect to the algorithm. Sampling frequency can be determined by running several simulations to choose which $f_{s}$ is the most stable when test with various distances. Several tests have been conducted to test if the error of estimated distance is increases or decreases. It is proven that the value of estimated fault resistance does affecting the accuracy of the distance algorithm. This means that a correction technique is needed to minimize the estimated earth fault distance error. Overall, the presented results shows that the distance algorithm and correction technique can be used as a solution to locate the earth fault location.

\section{ACKNOWLEDGEMENTS}

The authors would like to thank Universiti Malaysia Perlis (UniMAP) and Ministry of Higher Education Malaysia for providing research facilities and funding for the project via Fundamental Research Grant Scheme (Ref: FRGS/1/2016/TK04/UNIMAP/02/9). 


\section{REFERENCES}

[1] M. F. A. Fattah and M. Lehtonen, "Transient-based Protection as a Solution for Earth-fault Detection in Unearthed and Compensated Neutral Medium Voltage Distribution Networks," PQ2010 7th Int. Conf. - 2010 Electr. Power Qual. Supply Reliab. Conf. Proc., pp. 221-228, 2010.

[2] M. Gerin, "Protection Guide," ART.065193, 2006.

[3] X. Yuqin and C. Zhiye, "The Method for Automatic Compensation and Detection of Earth Faults in Distribution Network," pp. 1753-1757, 2002.

[4] J. Lorenc, et al., "Detection of the Intermittent Earth Faults in Compensated MV Network," in 2003 IEEE Bologna PowerTech - Conference Proceedings, vol. 2, pp. 590-595, 2003.

[5] M. F. A. Fattah and M. Lehtonen, "A Probabilistic-based Technique using Transient RMS Currents for Earth Fault Detection in Medium Voltage Distribution Networks," 10th IET International Conference on Developments in Power System Protection (DPSP 2010). Managing the Change, pp. 111-111, 2010.

[6] M. R. Adzman, et al., "An Earth Fault Location Scheme for Isolated and Compensated Neutral Distribution Systems," Int. Rev. Electr. Eng., vol/issue: 8(5), pp. 1520-1531, 2013.

[7] G. Buiges, et al., "Signal Injection Techniques for Fault Location in Distribution Networks," 2012 Int. Conf. Renew. Energies Power Qual., vol/issue: 1(10), 2012.

[8] A. H. Eldin, et al., "Detection of High Impedance Faults in Medium Voltage Distribution Networks Using Discrete Wavelet Transform," 22nd International Conference on Electricity Distribution, vol. 202, pp. 562- 567, 2012.

[9] S. Hänninen and M. Lehtonen, "Earth Fault Distance Computation with Fundamental Frequency Signals Based on Measurements in Substation Supply Bay," VTT Tied. - Valt. Tek. Tutkimusk, vol. 2153, pp. 3-40, 2002.

[10] Novosel, et al., "United States Patent," 1998.

[11] S. Borroy and M. García-gracia, "New Fault Location Method for Up-to-date and Upcoming Distribution Networks," 23rd International Conference on Electricity Distribution, Lyon, vol. 1290, 2015,

[12] P. Imrišs, "Transient Based Earth Fault Location in $110 \mathrm{kV}$ Subtransmission Networks," Helsinki University of Technology, 2006.

[13] S. Hänninen and M. Lehtonen, "Characteristics of Earth Faults in Electrical Distribution Networks with High Impedance Earthing," Electr. Power Syst. Res., vol/issue: 44(3), pp. 155-161, 1998.

[14] A. H. A. S. Abdul Saad, et al., "Into Statistics," 2012.

[15] X. Su, et al., "Linear Regression," Wiley Interdiscip. Rev. Comput. Stat., vol/issue: 4(3), pp. 275-294, 2012.

[16] N. J. Salkind, “Encyclopedia of Research Design,” Encycl. Res. Des., vol. 1, pp. 1187-1190, 2010.

\section{BIOGRAPHIES OF AUTHORS}

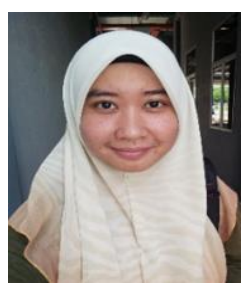

Nur Shazlin Bakhtiar Jamili was born in 1992, Penang, Malaysia. Diploma and Degree holder from Universiti Malaysia Perlis in 2013 and 2016 in Electrical System Engineering. Currently studying for Master in Science of Electrical System Engineering doing research in fault detection and localization. Her area of interest involved fault localization in medium voltage distribution network.

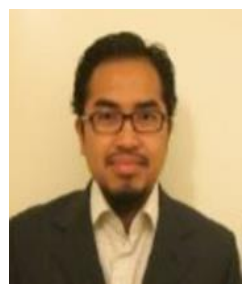

Mohd Rafi Adzman was born in Selangor, Malaysia, in 1976. He received the B.Eng. (Hons.) degree from the MARA University of Technology Shah Alam, Malaysia, in 2001, the master's degree in electrical engineering in 2006, and the Ph.D. degree from Aalto University in 2014. He has been with University Malaysia Perlis since 2006 as a Lecturer. His areas of interest include earth fault problem, distribution automation, preventive maintenance, and power quality.

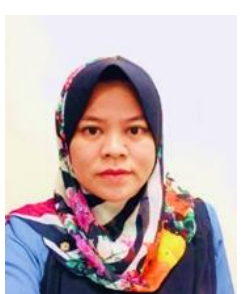

Siti Rafidah Abdul Rahim obtained her Diploma in Electrical Engineering (Power) from Universiti Teknologi Malaysia (UTM) in 1999, Bachelor of Electrical Engineering (Hons) and MSc in Electrical Engineering from Universiti Teknologi MARA in 2003 and 2006 respectively. She is currently senior lecturer at School of Electrical System Engineering, Universiti Malaysia Perlis (UniMAP), Perlis, Malaysia. Her research interest includes AI application in power system, power quality and distributed generation (DG). She is a member of IEEE Power and Energy Society, IACSIT and IAENG. 

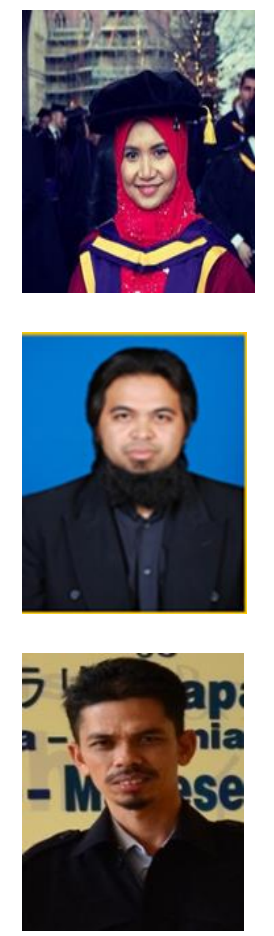

Samila Mat Zali received the B.Eng. and M.Sc. degrees from the National University of Malaysia in 1999 and 2002, respectively, and the Ph.D. degree from The University of Manchester, Manchester, U.K., all in electrical, electronic, and system engineering. Currently, she is working as a Lecturer at the Universiti Malaysia Perlis, Perlis, Malaysia.

Muzamir Isa was born in Perlis, Malaysia in 1979. He received the B.Eng. in electrical engineering (Hons) from the Universiti Teknologi Malaysia (UTM), Skudai, Johor, Malaysia in 2001, the M.Eng. in electrical engineering from the Tun Hussein Onn University of Technology, Johor, Malaysia in 2004 and Ph.D. degree from Aalto University, Finland in 2012. His research interests are partial discharge measurement, detection and location technique, and power system transient studies including EMTP-ATP simulation. Currently, he is associate professor at Universiti Malaysia Perlis (UniMAP).

Noor Hasnizam Hanafi obtain his Diploma in Electrical Engineering (Power) from Institute Teknologi Mara (ITM) in 1996, and his Bachelor of Engineering in Electrical Engineering (Power) from Universiti Teknologi Mara (UiTM) in 1999, and his Master of Science (Electrical) from Universiti Tun Hussein Onn Malaysia (UTHM) in 2005. Currently, he is lecturer at Universiti Malaysia Perlis (UniMAP). 